\title{
A prescriptive framework for recommending decision attributes of infrastructure disaster recovery problems
}

\author{
Milad Zamanifar ${ }^{1} \cdot$ Timo Hartmann $^{1}$
}

Accepted: 12 July 2021 / Published online: 23 July 2021

(c) The Author(s) 2021

\begin{abstract}
This paper proposes a framework to systematically evaluate and select attributes of decision models used in disaster risk management. In doing so, we formalized the attribute selection process as a sequential screening-utility problem by formulating a prescriptive decision model. The aim is to assist decision-makers in producing a ranked list of attributes and selecting a set among them. We developed an evaluation process consisting of ten criteria in three sequential stages. We used a combination of three decision rules for the evaluation process, alongside mathematically integrated compensatory and non-compensatory techniques as the aggregation methods. We implemented the framework in the context of disaster resilient transportation network to investigate its performance and outcomes. Results show that the framework acted as an inclusive systematic decision aiding mechanism and promoted creative and collaborative decision-making. Preliminary investigations suggest the successful application of the framework in evaluating and selecting a tenable set of attributes. Further analyses are required to discuss the performance of the produced attributes. The properties of the resulting attributes and feedback of the users suggest the quality of outcomes compared to the retrospective attributes that were selected in an unaided selection process. Research and practice can use the framework to conduct a systematic problem-structuring phase of decision analysis and select an equitable set of decision attributes.
\end{abstract}

Keywords Attributes $\cdot$ Decision-making $\cdot$ Disaster $\cdot$ Environment $\cdot$ Resilience $\cdot$ Problem structuring

\section{Introduction}

Decision analysis is broadly used for planning and solving problems concerning contemporary challenges such as disaster risk management, resilience planning and risk assessment, which often integrate multiple objectives and decision attributes. When responding to risks in environmental systems such as climate change and hazard-induced disasters, several objectives and attributes are involved covering multifaceted characteristics of a modeled problem. Identifying the underlying decision attributes is an essential, preliminary step in the decision-making modeling process (Keeney 2007; Belton and Stewart 2012). However, in both practice and research, systematic approaches towards the selection of attributes are either rare or inadequately applied which

Milad Zamanifar

Milad.Zamanifar@gmail.com

1 Department of Civil and Building Systems, Technical University of Berlin, Gustav-Meyer-Allee 25, 13355 Berlin, Germany hinders the identification of contextual, representative, and complete attribute sets (Dale et al. 2015; Niemeijer and de Groot 2006; Tiesmeier 2016). Attributes are often selected without the contextual justification or formal approach needed to shift speculative intuitions to rational judgments (Tiesmeier 2016). This issue has been shown in many decision-making contexts, including Disaster Recovery Planning of Transportation Network (DRPTN) (Zamanifar and Hartmann 2020). DRPTN is a decision-making context in which optimized recovery operation plans are identified to increase the resilience of transportation systems. Recovery interventions respond to the disruptive impact of hazards to restore an expected performance of a transportation network with repair and reconstruction operations. The extent to which the outcomes of DRPTN decision models are effective and reliable relies on the quality of attributes integrated into the decision modeling process. Therefore, selecting tenable decision attributes is critical for complex and sensitive problems such as disaster recovery and resilience planning due to the socioeconomic and environmental consequences of decisions (Sandri et al. 2020; Beling 2013). However, a 
gap in conceptual or systematic support for the selection process of DRPTN attributes exists. Based on this premise, the current paper is a response to the call of several studies for an approach that allows a systematic and transparent selection process of contextual decision attributes (Zamanifar and Hartmann 2020; Ha and Yang 2018; Tiesmeier 2016; Vaidya and Mayer 2016; Dale et al. 2015). Therefore, we propose a framework in the form of a decision aid mechanism that supports and facilitates the selection of attribute sets. In doing so, we formalize the process of attribute selection as a screening-utility choice problem, since "the problem of choosing between various formulations can itself be represented as a complex decision-making problem" (Mitroff and Featheringham 1974). As part of the developed framework, we formulated a prescriptive multi-criteria decision model. The model incorporates ten criteria as the evaluation factors based on the literature of Multiple-Criteria Decision Analysis (MCDA) and a combination of compensatory and non-compensatory techniques as the aggregation and evaluation method. We used this model in three sequential stages of evaluation to assist decision-makers (DMs) in assessing the performance of both attributes in isolation and attributes in sets. Once the framework was developed, we tested it in a real-life problem of disaster recovery planning and analyzed the results together with the application process of the framework.

Although the framework (supposedly) possesses the capacity to be generalized to various decision contexts, mainly those that address complex decision problems with multiple objectives or criteria, we chose to explore its performance in the context of recovery planning of transportation networks after natural and socio-natural hazards. On this ground, we collected decision attributes from the literature of DRPTN and experts' opinions as the input of the model. Then, we held a workshop with experienced emergency managers as the DMs for conducting the evaluation of inputted attributes following the flowchart of the framework. Results suggest that the framework is capable of facilitating a degree of supervision over the selection process and promoting critical and creative thinking. DMs were able to systematically evaluate attributes and collaboratively produce a ranked list and a set of attributes. The implementation of the developed framework revealed satisfactory application from the users' point of view. We also employed several analyses, including typological examination of the set, properties of the selection process, and the feedback of experts, to investigate the quality of the attributes while further experimental evidence is required to discuss the attributes' performance.

The rest of the paper is structured as follows: in the next section, we argue the necessity of this research and highlight the existing knowledge gap. In Sect. 3, we discuss the existing attribute selection approaches and how the proposed framework can situate itself among them, inviting the readers to understand the innovative aspects and contributions of this study. Section 4 illustrates the evaluation factors as the criteria of the developed decision model and the structure of the designed decision environment. Section 5 presents the methods that we employed and developed to construct, implement, and analyze the framework. Additionally, this section describes how users can adopt and apply the framework to their decision problems. Section 6 reports the results of implementing the framework and offers an analysis of its application. The Sect. 7 provides a discussion as to how results fulfill the objectives of this research and support the contributions. This section also points out some limitations involved with the decision modeling and implementation of the framework. Finally, the paper is concluded in Sect. 8.

\section{Knowledge gaps and the necessity}

The attribute set of a decision model represents essential problem-related characteristics and the behavior of the modeled system (Keeney and Gregory 2005). The degree to which this representativeness is preserved within attributes indicates the directness of attributes. A primary purpose for establishing a set of attributes is to disaggregate a complex decision problem into more analytically tractable components while maintaining the representativeness and collectivity of the modeled problem as direct as possible. Therefore, a well-thought-out attribute set can increase the likelihood of representativeness, directness, and completeness of a decision model. Despite the critical and fundamental role of attributes in decision analysis, the inadequacy of problem structuring and efforts for attributes identification in the decision modeling process is well documented (see, e.g., von Winterfeldt and Fasolo 2009; Tiesmeier 2016; Belton 1999). Maier and Stix (2013), Belton (1999), and Keeney and Gregory (2005), among others, raised awareness that far too little attention has been paid to the manner in which a list of attributes and their contextual structures are obtained. Specifically, much of the literature on decision analysis neglects the role of problem structuring and thorough investigations on attributes as the primary task for structuring a decision-making model (Franco and Montibeller 2010). Similarly, in practice, Girod et al. (2003) observed that during three workshops involving experts engaged in the decision-making process of an engineering design, less than $8 \%$ of the time was used to identify the criteria for the targeted problem (Girod et al. 2003). Thus, it is hardly clear to what extent the model's recommended solution holds for the real system (Corner et al. 2001). This issue is crucial for Decision Support Systems (DSS) in disaster recovery and environmental models that seek to present decision-making methodologies associated with tremendous socioeconomic 
loss or gain (Goujon and Labreuche 2015; McDaniels et al. 2015).

A destructive or disruptive event that hinders access within a transportation network or adversely influences the safety and efficiency of a network's mobility, to any extent or period that exceeds the affected community's socioeconomic tolerance and coping capacity, can be perceived as a disaster. Consequently, the concept of resilience is employed to mitigate, postpone, or eliminate the likelihood of a hazard transforming into a disaster. Resilience is "the "shear zone' between (dynamic) adaptation and (static) resistance" (Alexander 2013). More specifically, disaster resilience in the transportation network context refers to plans and actions that improve the recovery potential of network performance and adapt to the components' failure during and after a disaster. Non-resilient transportation infrastructure leads to significant economic loss, threatens society's health and well-being, and exacerbates the consequence of hazard exposure and vulnerability (Kurth et al. 2020; Koks et al. 2019). To increase resilience, developing reliable disaster recovery planning is essential to meet the restorative, rapidity, redundancy, and resourcefulness properties of resilient infrastructures (Bruneau et al. 2003; Liu et al. 2020). Post-disaster recovery planning of a transportation network is a fundamental characteristic for a disaster resilient community, usually formulated as a decision model to rank or optimize the order of links for recovery operations (Zhang et al. 2017; Aydin et al. 2018; Rouhanizadeh and Kermanshachi 2019). To improve disaster recovery planning, one must establish a set-up in which DMs can make informed decisions concerning the attributes integrated into the disaster recovery decision model. Therefore, it is of utmost importance that disaster recovery models harness the benefit of properties of a desirable attribute set while engaging with such ever evolving and critical problems (Pearson et al. 2018; Quigley et al. 2019).

Studies have pointed out the role of MCDA in the decision modeling processes used for risk assessment, resilience, and recovery planning (e.g., Cegan et al 2017; Rand et al. 2020; Manyaga et al. 2020). Keisler and Linkov (2014) highlight the utility and favorability of MCDA, such as linear additive scoring models in decision recommendations for environment models. Rand et al. (2020) argue that disaster recovery planning requires decision models and decision support systems for informed decision-making since the recovery of infrastructure is coupled to at-risk communities' resilience. While the application of MCDA in prescriptive decision models is evident, it has also been vastly employed for problem structuring, identifying decision values, or relevant metrics under the guide of frameworks (e.g., Fox-Lent et al. 2015; Convertino et al. 2013; Linkov et al. 2018). For example, Linkov et al. (2013) developed the "Resilience Matrix" framework to identify metrics and to calculate the performance scores for critical functions related to disaster resilience of a defined system. Keeney and McDaniels (1992) highlight that a key component in decision analysis is the use of facilitation to identify values and frame the multicriteria problem (Keeney and McDaniels 1992). Moreover, Keisler and Linkov (2014) also argue that the value of interventions in decision analysis is not only in the scoring and rating of alternatives but the ability to facilitate discussion and articulating viewpoints and decision values. They further point out a need for tools and approaches to allow analysts to measure and discuss the desirability of hypothetical alternatives. This paper seeks to offer a facilitation process that helps DMs process values in a certain decision context and to more reliably select decision attributes. The necessity of this facilitation escalates when the decision context embeds disaster resilience and recovery planning.

While the critical importance of attributes in decision analysis is generally recognized, it is still insufficiently addressed in the disaster risk management context. For instance, DRPTN studies have introduced a wide range of attributes to optimize or rank recovery operations of transport lifelines. However, only $22.5 \%$ of studies have illustrated how the problem of DRPTN is structured or decision attributes are selected (Zamanifar and Hartmann 2020). Even with highly visible decision processes, insufficient thought is typically given to the identification and choice of attributes (Keeney and Gregory 2005), while in the context of DRPTN, variables and factors are often inherently uncertain. This challenge is not limited to the disaster management field, but has been shown in other contexts too. For instance, Desmond (2007) outlines that there is a lack of methodologies that assist in identifying attributes or alternative sets in the strategic environmental assessment field. Similarly, Ha and Yang (2018) share the same point of view and recognize this gap in the infrastructure performance assessment domain. They highlight that studies lack a systematic approach capable of processing and incorporating adequate information, such as decision factors, into the decision problem. Furthermore, Niemeijer and de Groot (2006) argue that the selection process of attributes is mainly subject to arbitrary decisions and called for a clear process for selecting attributes, while Lin et al. (2009) believe that attribute selection processes in most cases are insufficiently systematic and transparent. Tiesmeier (2016) identifies the same shortcoming in the real estate domain, reported incomplete lists, as well as high inconsistency across studies while identifying attributes. He underscores that very few studies fully justify the adoption of the chosen attribute systems. Moreover, Ma et al. (2017) highlight that answering the question of how to select the optimal decision attributes is a compelling future research direction and a critical process for many domains that use decision analysis. Fekete (2019) takes a similar stance and emphasizes the demand 
for guidance on attribute selection in disaster social vulnerability context. Overall, many decision-making models fall short in benefiting from a reproducible and transparent model that assists analysts in selecting decision factors (Tiesmeier 2016). That is, the task of attribute identification itself remains a challenge that has not been adequately met (Vaidya and Mayer 2016; Dale et al. 2015) which has led to a call for a systematic guide as a reliable decision aid framework to select attributes of decision problems.

\section{Current approaches towards the selection of attributes}

Decision attributes are often chosen based on expert opinions, literature, or a combination of the two. The expertbased approach refers to drawing out information from stakeholders, actors, and DMs to articulate important decision factors in a specific context (e.g., McIntosh and Becker 2020; Elboshy et al. 2019; Mirzaee et al. 2019). The expertbased approach has the benefit of being based on the experiences of experts who possess the knowledge contextually related to the values of the decision context (assuming that the desired properties of stakeholder analysis, interviews, inclusion criteria of interviewees, and aggregation methods are met). However, on the one hand, it falls short in including existing literature and might fail in providing a complete list of attributes. On the other hand, expert opinions are assumed reliable sources for providing preferences and values in a decision-making process as long as they possess adequate decision-relevant knowledge, experience, or stake (Bond et al. 2008). Nevertheless, empirical studies suggest that individuals' striking inability to understand their objectives, values, and preferences, and their markedly deficiency in communicating them is a plausible consideration (Barron and Barret 1996; Kahneman et al. 1982). Thus, expert-driven attributes could be a product of bias and error-prone efforts in a limited amount of time and lesser in-depth thinking on a specific problem (Girod et al. 2003; Tiesmeier 2016). In order to shift towards a less interview-intensive and intuitive approach, some studies used the available literature to identify and select the attributes of a decision problem (e.g., Herrera and Kopainsky 2020; Merad et al. 2013; Yu and Solvang 2017). Although selecting attributes based on existing literature is an accepted approach, critique holds that literature might disregard some aspects of a problem due to its limitations in accessing comprehensive data, communication constraints, and simplifying assumptions. When one adds the challenge of dynamic nature of problems, temporal limitation of empirical studies, and the contextual inconsistency of literature-recommended attributes to the problem at hand, therefore, sole reliance on existing literature might not sufficiently ensure an exhaustive and error minimized approach for selection of attributes. To shape a more complete, up-to-date, and practical set of attributes, the third approach is a combination of expert opinion and previous literature within the field (e.g., Walpole et al. 2020; Caruzzo et al. 2020; Kassem et al. 2016). While this approach maximizes the exhaustiveness of the inclusion of attributes, it yields a broad list of attributes from which some must be selected intuitively. Nevertheless, objectively supervise this intuition to select a viable attribute set remains a challenge. Thus, a prescriptive model as a decision intervention is needed to formulate and solve the choice problem of the selection among a finite number of alternatives.

To overcome this challenge, the model-based approach has been introduced to systematically select attributes that cover the concerns and values of the problem under consideration. Accordingly, a few studies provide model-driven attributes by formulating the selection process of attributes as a choice problem (Cinelli et al. 2020; Höfer et al. 2020; Otto et al. 2018; Rossberg et al. 2017; Dale et al. 2015; Convertino et al. 2013). Regardless of the source of the alternative pool, these studies evaluate candidate attributes based on properties of the desired attribute and apply a systematic process to select the attribute set. Properties of the desired attribute are factors that evaluate the merits of an attribute, such as unambiguous, operational, and direct (see, e.g., Keeney 1992). Our work extends this strand of approaches with some innovation in the formulation approach, capability, and generalizability of the application. First, as a general guide for constructing a framework that seeks to prescribe a decision, we followed the recommended structure of the prescriptive decision analysis. Prescriptive decision analysis is an intervention process to model a rational choice with the recommended steps of problem structuring, preference elicitation, evaluation/aggregation, and solution handling (Clemen 1996; Keeney 1982). Second, we introduced three stages of evaluation that led us to three decision regions and subsequently three decision rules. The multi-stage evaluation process allows the incorporation of ten evaluation factors without the urge to introduce hierarchy into the criteria system or increasing the complexity of the modeled problem. This architect of the evaluation environment also leads to a thorough yet cognitively manageable evaluation process. Third, the built-in screening evaluation stage grants the inclusion of candidate attributes from various sources such as literature and expert opinions. Fourth, the developed decision model not only evaluates attributes but also evaluates sets of attributes in the third decision region. Fifth, we proposed a comprehensive and illustrated framework to support the implementation of the decision model that can be used for future research and practice as well as by those who are not necessarily an expert in decision analysis. Therefore, the added value of this research is: 
1. Formulating the process of selecting attributes of the DRPTN problem as a prescriptive decision model to aid the attribute selection process and DMs' knowledge acquisition;

2. Exploring the performance of integrating compensatory and non-compensatory decision rules and introducing a new application for this integration;

3. Presenting a tractable and user-friendly framework to assist systematic multi-stage evaluation and selection of tenable decision attributes of disaster recovery planning problems.

The framework aims to systematically process the DMs' inputs and develop contextual decision values and assist them in selecting an effective, operational, and complete set of decision attributes. The contribution of this paper is the proposed framework and the embedded decision model. The practical implication of results is to help decision analysts to make an informed choice and tenable decisions within the construction of a decision-making model. Therefore, scholars who develop multi-objective or multi-attribute decision models can use this framework in the problem-structuring phase of their modeling process since "one of the most important determinations of a problem's solution is how that problem has been represented or formulated in the first place" (Mitroff and Featheringham 1974).

\section{Evaluation factors and the decision environment}

As decision criteria, we adopted existing evaluation factors of attributes, or "properties of a good attribute" (Keeney 1992), by conducting a review in MCDA problem structuring literature. Based on the recommendation of Franco and Montibeller (2010), these evaluation factors are adopted to address whether attributes are operational and relevant to the decision context, the way they measure the performance of alternatives, and how they are aligned to the objectives. In the literature, except for Roy (1996), the properties of an attribute and a set of attributes are not distinguishably discussed. Therefore, we took into account the "properties of a good set of attributes" by identifying the factors that address the characteristics of an attribute set. We also interpreted "measurability" to "certainty of measure" to tailor a set of evaluation factors for our particular problem, since we had good reasons to believe that after a disaster, the certainty of the measuring associated with an attribute reduces the uncertainty of the value of an objective. Table 1 shows ten adopted evaluation factors, where seven count for members of an attribute set while three factors evaluate sets of attributes.

Evaluation factors are divided into three decision regions based on whether they evaluate the performance of individual attributes or a set of attributes, and whether they address the property of necessary or sufficient conditions of the desired attribute. That led us to three decision regions for which we assigned each a known decision rule: compensatory, non-compensatory, and optimal. The reason for designing a multi-stage evaluation strategy is to take into account both the properties of evaluation factors and properties of alternatives of this specific problem. Therefore, while in the first two regions, attributes are evaluated individually, in the third region, they are evaluated as a set. For the properties of evaluation factors, the first region includes factors that are necessary for attributes to meet. Hence, compromise among factors is not desired which justifies the use of noncompensatory decision rules. The second decision region includes factors that can compensate for each other, which makes using a compensatory decision rule reasonable. In the third decision region, the optimal performance of three evaluation factors is the target of the evaluation. Additionally,

Table 1 The evaluation factors for members of an attribute set and sets of attributes (Zamanifar and Hartmann 2021)

\begin{tabular}{|c|c|c|}
\hline Evaluation factors & For members For set & Suggested by \\
\hline Coherency with objectives & & Belton (1999), Majumder (2015), Gregory and Failing (2002) \\
\hline Operational & & $\begin{array}{l}\text { Baker et al. (2001), Belton (1999), Dodgson et al. (2009), Belton and Stewart (2012), } \\
\text { Keeney (2007) }\end{array}$ \\
\hline Discriminative & & Baker et al. (2001), Gregory and Failing (2002) \\
\hline Understandable & & Keeney (2007), Belton and Stewart (2012), Roy (1996) \\
\hline Direct & & Belton and Stewart (2012), Majumder (2015) \\
\hline Certainty in measure & & Gregory and Failing (2002), Majumder (2015) \\
\hline Representativeness & & $\begin{array}{l}\text { Roy (1996), Baker et al. (2001), Dodgson et al. (2009), Belton and Stewart (2012), Keeney } \\
\text { (2007) }\end{array}$ \\
\hline Completeness & & Belton and Stewart (2012), Dodgson et al. (2009), Roy (1996), Baker et al. (2001) \\
\hline Non-redundant & & $\begin{array}{l}\text { Belton and Stewart (2012), Dodgson et al. (2009), Baker et al. (2001), Roy (1996), Gregory } \\
\text { and Failing (2002) }\end{array}$ \\
\hline Concise & & Belton (1999), Majumder (2015), Gregory and Failing (2002), Baker et al. (2001) \\
\hline
\end{tabular}


designing separate decision regions allowed us to reduce the complexity of the evaluation process and avoid possible errors and biases associated with a hierarchized criteria structure such as systematic spitting bias (Hämäläinen and Alaja 2008) influence of the type of asymmetry in a hierarchy (Marttunen et al. 2017), and larger variance in weights (Jacobi and Hobbs 2007). Breaking the evaluation into three discrete stages resulted in a more cognitively manageable process when assessing alternatives' performances with the maximum number of evaluation factors in each region not exceeding four (Cowan 2010). Figure 1 demonstrates the decision regions and corresponding decision rules of the model.

The evaluation begins with the screening region, as the filtering phase of the decision process with a non-compensatory decision rule. Thus, alternatives, which fail to satisfy the factors of this region, will be either removed or considered for redefinition. We postulate a genuine interest in the first three evaluation factors which we call "concrete factors". Therefore, the screening region excludes attributes that; (1) are not relevant to the decision context (coherency with objective; (2) are not commensurable in a consistent manner and with a reasonable amount of effort (operational); and (3) are not clearly distinguishing among all alternatives to perform a comparison (discriminative). By establishing a screening region, we ensure that concrete factors are not ignored in compensation for other evaluation factors. Attributes that meet the three evaluation factors of the screening region move into the choice region. The choice region operates with a compensatory decision rule; therefore, a

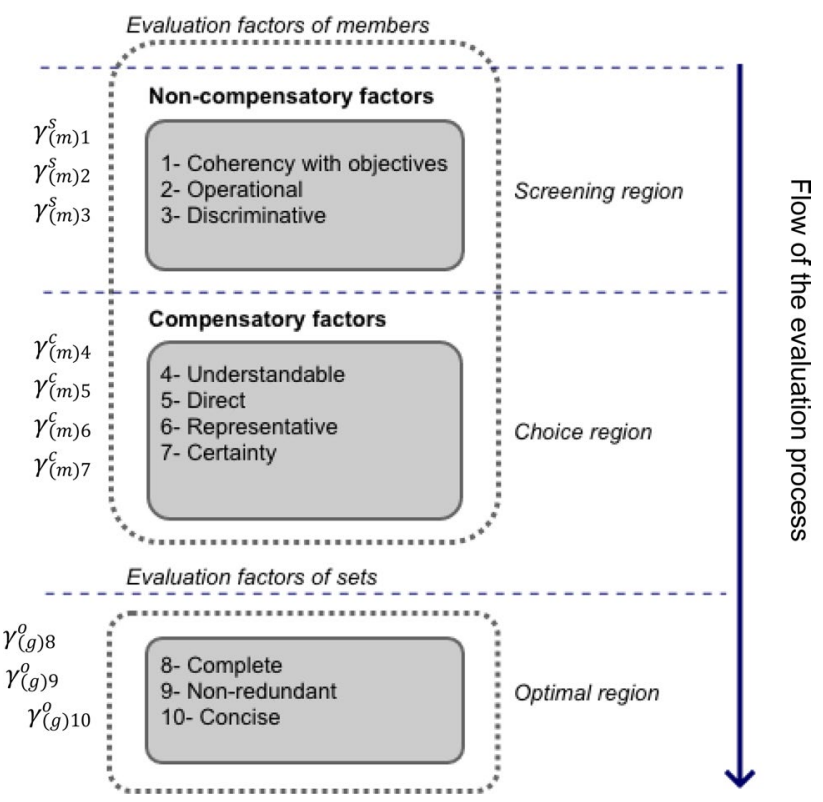

Fig. 1 The structure of evaluation factors, notions, decision regions, and decision rules for members and sets compromise among evaluation factors in this decision region is desired. The choice region evaluates the attributes based on the four criteria as "choice factor", including (1) "understandable" when it has a clear and unambiguous definition; (2) "certainty" when it yields a certain measured value for the objectives; (3) "directness" when it directly measures the primary objective of the decision problem; and (4) "representative" when it represents the essential characteristics of the system. The third group of factors evaluates "sets of attributes" based on the optimal decision rule. The optimal decision rule can be regarded as the optimized outcome for a set of attributes that capture the maximum key aspects of all objectives (completeness) with an optimized size of the attribute set (concise). In addition, the set should not contain a double-counting attribute (non-redundancy), which can be expressed as the constraint of the optimal region (Zamanifar and Hartmann 2021).

\section{Methodology and the developed framework}

This section presents the methodology for developing the attribute selection framework, the framework itself, and methods used for implementing and evaluating the framework. Table 2 demonstrates the adopted methods in the frame of the prescriptive decision analysis. While the problem-structuring phase was presented in Sect. 4, this section discusses methods and their applications for the remaining tasks of our research design.

\subsection{Models of transition and aggregation}

Both compensatory and non-compensatory approaches have their own application and advantages; hence, a contrast between them is not meaningful. Nonetheless, there are decision contexts in which employing either of compensatory or non-compensatory decision rules alone cannot meet the characteristic of the modeled problem. Non-compensatory aspect-based methods rely on a sequential elimination approach based on sorted criteria that usually leads to a straightforward selection of the most preferred alternative. Non-compensatory methods are widely used in normative decision theory (see, e.g., Gigerenzer and Goldstein 1996; Gigerenzer and Gaissmaier 2011) since they are consistent with the concept of bounded rationality. However, aspectbased non-compensatory methods overlook the existence of some criteria and a part of the available information in the decision context is often regarded as irrelevant (Rothrock and Yin 2008). This is because most of the information collected on alternatives will not play a role in the evaluation process (Munda 2005). Therefore, they are limited in application to conditions when non-compensatory is the desired 
Table 2 An overview of the adopted methods and task for developing the proposed framework

\begin{tabular}{|c|c|c|}
\hline Purpose & Task & Method \\
\hline \multirow[t]{2}{*}{ Problem structuring } & Adopting evaluation factors & Content analysis \\
\hline & Defining decision regions and assigning decision rules & Based on the property of factors and alternatives \\
\hline Preference elicitation & Identifying the relative importance of compensatory evaluation factors & Cardinal ranked-based weighting approach \\
\hline Problem solving & $\begin{array}{l}\text { Combination and extension of compensatory and non-compensatory } \\
\text { MADM techniques }\end{array}$ & $\begin{array}{l}\text { Multi-attribute value theory } \\
\text { Elimination by aspect }\end{array}$ \\
\hline \multirow[t]{4}{*}{$\begin{array}{l}\text { Implementation and } \\
\text { solution handling }\end{array}$} & Collecting data & $\begin{array}{l}\text { Systematic review } \\
\text { Questionnaire }\end{array}$ \\
\hline & Implementing methodology & Workshop with decision-makers \\
\hline & Analyzing data & Proposed methodology \\
\hline & Analyzing results & $\begin{array}{l}\text { Performance observation and feedback survey } \\
\text { Retrospective comparison } \\
\text { Typology of selected attributes }\end{array}$ \\
\hline
\end{tabular}

rule of the entire decision context. Meanwhile, compensatory methods cannot be applicable when some criteria are infinitely more important than others. With this preferential model, compensatory methods could lead to an undesirable outcome as the choice might fail to meet the minimum level of desirability in one or more criteria. Consequently, compensatory methods might not be efficient when a part of the decision context does not accept trade-offs among some of the criteria. Both compensatory and non-compensatory methods, when they are used individually, assume that the same decision rule holds for all criteria. Therefore, for some problems, they are unrepresentative of the decision strategy they seek to represent. For the benefit of our framework, we combined the application of compensatory and non-compensatory methods and designed two decision regions for appraising isolated attributes within a single decision system. Integrating compensatory and non-compensatory decision rules maximizes the amount of incorporated information and allows its specificity within the modeling procedure. The first decision region performs in a perfectly non-compensatory fashion, while the second decision environment allows for a compensatory interaction among the factors. The first decision region is absolutely preferred to the second decision region which we mathematically formulated as part of the transition between two regions.

For the non-compensatory region, we adopt the axioms presented with the lexicographical choice concept (Tversky 1972) and formulated it to an aspect-based screening condition as it is formalized in Eq. (1). For the choice region, we directly used the well-known Multi-Attribute Value Theory (MAVT) (Keeney and Raiffa 1993) and contextualized it to the local variables of our decision context shown in Eq. (2). In doing so, the following mathematical expression represents the integration of compensatory and non-compensatory decision rules. The condition expressed in Eq. (1) indicates that alternative $\mathrm{A}$ is preferred to $\mathrm{B}$ when two alternatives have equal performance on a set of factors in a binary format while there exists at least one factor that alternative $B$ is not satisfying. Accordingly, for the first three evaluation factors (coherency with objective, operational, and discriminative: $\gamma_{1}^{s}, \gamma_{2}^{s} \gamma_{3}^{s}$ ) of the screening region: Let $\Gamma_{s}=\left\{\gamma_{1}^{s}, \ldots, \gamma_{i}^{s}\right\}, \forall_{i} \in\{1, \ldots, h\}, h \geq 2$ be the finite set of already known Concrete factors of our screening region $(s)$ which is denoted by $s$. Now, suppose there exist a nonempty finite set called $\vartheta$ that $\vartheta_{\gamma_{i}^{s}}$ represents the importance degree among factor $\gamma_{i}^{s}$ where $V$ represents the preference of DMs on a factor and $V_{\gamma_{1}^{s}}=V_{\gamma_{2}^{s}}=V_{\gamma_{3}^{s}}$. Moreover, let $\Delta_{1}=\left\{\delta_{1}^{s}, \ldots, \delta_{j}^{s}\right\}, \forall_{j} \in\{1, \ldots, m\}, m>2$ and a positive integer define the set of competing alternatives and $\Psi_{i j}$ denotes the binary value of $i t h$ factor to $j$ th alternative where $\Psi_{i j} \in\{1,0\}$. Now consider $\delta_{j}^{s}$ and $\delta_{j+n}^{s} \in \Delta, \forall n>0$ then $\delta_{j}^{s}$ is lexicographically preferred to $\delta_{j-n}^{s}$ if, and only if:

$$
\left\{\begin{array}{l}
\Psi_{i j}^{\delta_{j}^{s}} \text { equals } 1 \text { for all } \Gamma=\left\{\gamma_{1}^{s}, \ldots, \gamma_{i}^{s}\right\} \\
\text { and, } \\
\exists \gamma_{i}^{s} \in \Gamma \text { that } \Psi_{i j}^{\delta_{j-n}^{s}} \text { equals } 0 .
\end{array}\right.
$$

Meanwhile, for the choice region with compensatory decision rule, we aggregate four evaluation factors of understandable, representative, direct, and certain $\left(\gamma_{(m) 4}^{c}, \gamma_{(m) 5}^{c}\right.$, $\left.\gamma_{(m) 6}^{c}, \gamma_{(m) 7}^{c}\right)$ with formulating MAVT for our problem. The transition from the screening region to the choice region can be shown: again, let $\hat{\Gamma}_{c}=\left\{\gamma_{1}^{c}, \ldots, \gamma_{i}^{c}\right\}, \forall_{i}$ $:\{1, \ldots, k\}, k \geq 2$ an integer for the new discrete finite set of Choice factors of the choice utility region $(c)$ which is denoted by $c$ such that $\hat{\Gamma}_{G} \cap \Gamma=\{\varnothing\}, \wedge \dot{\Gamma}_{c}>\Gamma_{s}$. Moreover, accept $\dot{\Delta}_{2}=\left\{\delta_{1}^{s}, \ldots, \delta_{j}^{s}\right\}, \forall_{j} \in\{1, \ldots, m\}, m>2$ as the choice set that already satisfied the set of $\Gamma_{s}$ in the screening region such that $\dot{\Delta}_{1} \subseteq \Delta_{2}$. Additionally, assume preference 
weight among factors follow $0>V_{\gamma_{1}^{c}}>V_{\gamma_{2}^{c}}>\ldots>V_{\gamma_{i}^{c}}$, then, without loss of generality, the utility of each alternative is:

$U_{i}\left(\delta_{j}^{c}\right)=\sum_{i=1}^{n} \omega_{i} \cdot \dot{\Psi}_{i j}\left(\delta_{j}^{c}\right), \quad i=1, \ldots, n$,

where $U_{i}\left(\delta_{j}^{c}\right)$ is the scaled utility function of alternatives, $\stackrel{\Psi}{\Psi}_{i j}$ denote the performance of attribute $i \in \Delta^{\prime}$ on alternative $\delta_{j}^{c} \in \Gamma^{\prime}$ as a single attribute value function, $\left(\delta_{j}^{c}\right)$ is the performance of alternative $j$ for attribute $i$ and $\omega_{i}$ is scaling factor projecting the importance weight of attribute $i, \sum_{i=1}^{n} \omega_{i}=1$. For further investigation on the axiomatic background of the Eq. (2), one can see the original work of Keeney and Raiffa (1993).

\subsection{Preference elicitation}

Imprecise weight elicitation is based on ordinal and cardinal values that DMs approximate regarding the relative importance of criteria. Ordinal information refers to the rank of criteria based on their importance, while cardinal information represents the relative range of intervals among assigned ranks. Ordinal methods such as Rank Ordered Centroid (ROC), Rank Sum (RS), and Rank Reciprocal (RR) (for a review, see, e.g., Roszkowska 2013) convert the rank of criteria to (surrogate) numerical weights. Unlike the approaches that are based on semantic and numerical scales, weight approximation methods assume that compelling DM to express their exact perceived values is cognitively demanding and refrain from obtaining viable preferences (Barron and Barrett 1996; Alfares and Duffuaa 2008). For example, Barfod and Leleur (2014) argue that DMs are more comfortable and confident with ranking the attributes rather than communicating their preferences by verbal scales. Roszkowska (2013) highlights that for a group of $\mathrm{DM}$ is easier to agree on rank-based sorting of items than to assigning precise numerical values. However, the critique also exists that preference elicitation following ordinal methods encounters information loss since these methods do not inquire or make use of information regarding the magnitude or intensity of preference among sorted items (Danielson and Ekenberg 2016). Rank-based methods, generally, rely on the centroid of ordered factors and do not require any further input from DMs on the preference difference between ordered pairs of factors. Some studies also report the victimized weight for lower-placed criteria due to large discrepancy between the highest and lower sorted criteria, suggesting the need for methods that incorporate cardinal information into the weight approximation process and generate "smoother" weight (Roberts and Goodwin 2002; Huang et al. 2011; Belton and Stewart 2012).

Building upon the existing weight approximation approaches (Kárný 2013; Salo and Hamalainen 2001; Barron and Barret 1996), we designed a rank-based tool to allow experts to communicate their cardinal and ordinal preference related to the relative importance of four compensatory evaluation factors. The reason that we customized a weight approximation approach instead of pure ordinal methods was first to avoid extreme weights that significantly marginalize the weight of lower factors (Belton and Stewart 2012), second to prevent equalizing impact on upper factors (Kunsch and Ishizaka 2019), and third to utilize the available cardinal information that ordinal methods often do not take into account (Danielson and Ekenberg 2016).

We used the input of six MCDA experts to suggest tradeoffs among the evaluation factors that represent criteria of a good attribute. In order to recognize participants as experts, we considered the fulfillment of three criteria consisting of research engagement in the MCDA field, current involvement in the field through MCDA-related publications in the last five years, and post-graduates holding academic research assistant positions. Since the properties of attributes in the decision-making context have been widely discussed in decision analysis and MCDA discipline, we chose to acquire the input of academic experts within this field. Experts provided ordinal information for evaluation factors by ranking them from the most important to the least important on a vertically $2 \mathrm{D}$ visualized slider. They then adjust the distance among the sorted evaluation factors to express their cardinal preferences. Therefore, while experts can communicate the ordinal preference by ordering the factors, they can also regulate the intervals among each pair of sorted factors to indicate the pairwise preference intensity. No numerical scale has been presented for experts on the slider and visuospatial scale was the interface for regulating the distances. The mathematical model that interprets the defined rank and intervals into numerical weights can be formally articulated by the following:

The input value for an evaluation factor $i$ is $d_{i} \wedge d_{1}=0$ where $d$ is Euclidean distance of factors assigned by experts to the Cartesian origin $O$ of the vertically visualized slider. Each evaluation factor is presented to experts as an item on this slider, while the first factors always remain at the origin $O$. The assigned location of each item represents experts' ordinal preferences. Since the most important factor is set as an item in the highest point of the slider, it is then logical to assume $d_{1} \geq \dot{d}_{2} \geq \dot{d}_{3} \geq \cdots \dot{d}_{n}$ for $\forall i \in n, 9 \geq n \geq 2$ where $d_{l}$ is the revisited distance of factor $i$ to a new origin that increases as do the preference of factors. This assumption allows for converting the growth of the distance from the origin equal to the growth of preference. Therefore, for $n=4$ evaluation factors of the choice region, we have 
$d_{1} \leq d_{2} \leq d_{3} \leq d_{4}$ which represents $d_{1} \geqslant d_{2} \geqslant d_{3} \geqslant d_{4}$. Now following the equations below, the relative importance of factors can be calculated:

$v_{\mathrm{o}}=\frac{\sqrt{\sum_{i}^{n}\left(d_{i}-\bar{d}\right)^{2}}}{(n-1)-k}+d_{\max }$

$\dot{d}_{\iota}=\left|\left(d_{i}-v_{o}\right)\right| * \ln \left|\left(d_{i}-v_{o}\right)\right| ; \forall i$

$w_{i}=\left(\dot{d} / \sum_{1}^{n} \dot{d}_{i}\right) * 100,(i=1, \ldots n)$

$w=w_{1} \gamma_{(m) 4}^{c}+w_{2} \gamma_{(m) 5}^{c}+w_{3} \gamma_{(m) 6}^{c}+w_{4} \gamma_{(m) 7}^{c}, \sum_{1}^{n} w_{i}=1, d \in \mathbb{R}, w_{i} \neq 0$

where $\bar{d}$ is the mean value of all distances from origin $O . v_{o}$ is the virtual origin point of the weight vector as a base for calculating the revised distance, $d_{i}$ is the initial distance for each interval that experts assign, $k$ is the number of evaluation factor with equal ordinal preference (if there is any), $n$ is the number of factors, $\dot{d}_{l}$ is the revised distance of each interval value to the $v_{o}$, and $w_{i}$ is the calculated weight of $i$ th factor when $\sum_{1}^{n} w_{i}=1$. We incorporated the exponential effect in Eq. (4) to prevent equalized weights while allowing the weight vector to count for both ordinal and cardinal preference input of DMs. Haung et al. (2011) argue that the non-linear distances between single dimension scores and ratios should produce smoother trade-offs. In addition, we know of no study that suggests preference of individual related to a sorted list of objects is distributed uniformly (see Roberts and Goodwin 2002). With this approach, we could shift the weight vector toward a flatter shape and, in the meantime, prevent significant discrepancy between the weight of the first and last factors.

By using the experts' input regarding the order and interval among four compensatory evaluation factors, the weight vector was delivered in the format of Eq. (6). Assuming that the preference for all factors is judgmentally independent, the preferential model of the four evaluation factors of the choice region, including understandable, representative, direct, and certain, $\left(\gamma_{(m) 4}^{c}, \gamma_{(m) 5}^{c}, \gamma_{(m) 6}^{c}, \gamma_{(m) 7}^{c}\right)$ can be shown as $\mathrm{th} \mathrm{e} \quad \mathrm{w}$ e i g h t ve c t o r $w=20.68 \gamma_{(m) 4}^{c}+36.56 \gamma_{(m) 5}^{c}+27.44 \gamma_{(m) 6}^{c}+15.32 \gamma_{(m) 7}^{c}$.

\subsection{The proposed framework}

We designed the framework based on the evaluation factors, their preferential model, and the decision rules as well as the adopted transition and aggregation logic. It consists of core nine steps which acts as a decision aiding toolkit for selecting attributes of DRPTN problems. Figure 2 provides a detailed flowchart and the process of applying the proposed framework.

The implementation of the framework begins with identifying the primary objectives of the original problem. The original problem refers to the problem for which the framework intends to select attributes. Since the framework embeds a choice model, the task in the second step is to develop a set of alternatives. The alternative pool is a set of candidate attributes as the input of the model for the evaluation process. Regardless of the approach used in constructing such a set, it is essential to establish an expanded and complete set of attributes from diverse sources such as literature, experts, stakeholders, actors, and decision-makers to obtain a "reasonably complete" list of attributes (Keeney 2007).

The third step is adopting the ten evaluation factors for the three evaluation stages as well as the relative importance among the four evaluation factors of the choice region presented in 5.1. In step four, Eq. (1) indicates that alternatives for which the necessary condition of all three screening factors is not held must be ruled out or redefined. Within the fifth step, the remainders of alternatives enter the choice region in which users can assign a numerical value for attributes' performance in relation to satisfying compensatory factors. Once each alternative has received the scores of the previous step, in step six, an additive aggregation method (Eq. 2) is recommended to rank the alternatives under the compensatory decision rule. During the evaluation, users can redefine or suggest new attributes to satisfy the screening evaluation factors or improve the performance on the choice evaluation factors, under the condition that the evaluation process iterates from the second step.

Concept mapping of ranked attributes is the aim of the seventh step, by assigning each ranked attribute from the previous step to its representing objectives. In accordance with Keeney's recommendation (Keeney 1992), we suggest the generic value tree as the concept mapping approach to aid in identifying the completeness of the attribute set. The last step inherits the ranked list of attributes from screening and choice regions that are classified within the organization of the conceptual value tree of the defined objectives. In this step, the task is to evaluate sets of attributes based on completeness, size, and nonredundancy. Using the value tree, the completeness of the set can be monitored in terms of covering all objectives. In the optimal region, the minimum size of the attribute set that satisfies the completeness of the set and does not contain a double-counting attribute is the selected attribute set. If the resulting ranked attributes of step seven could not cover all the objectives of the value tree, expanding the alternative pool is necessary. 


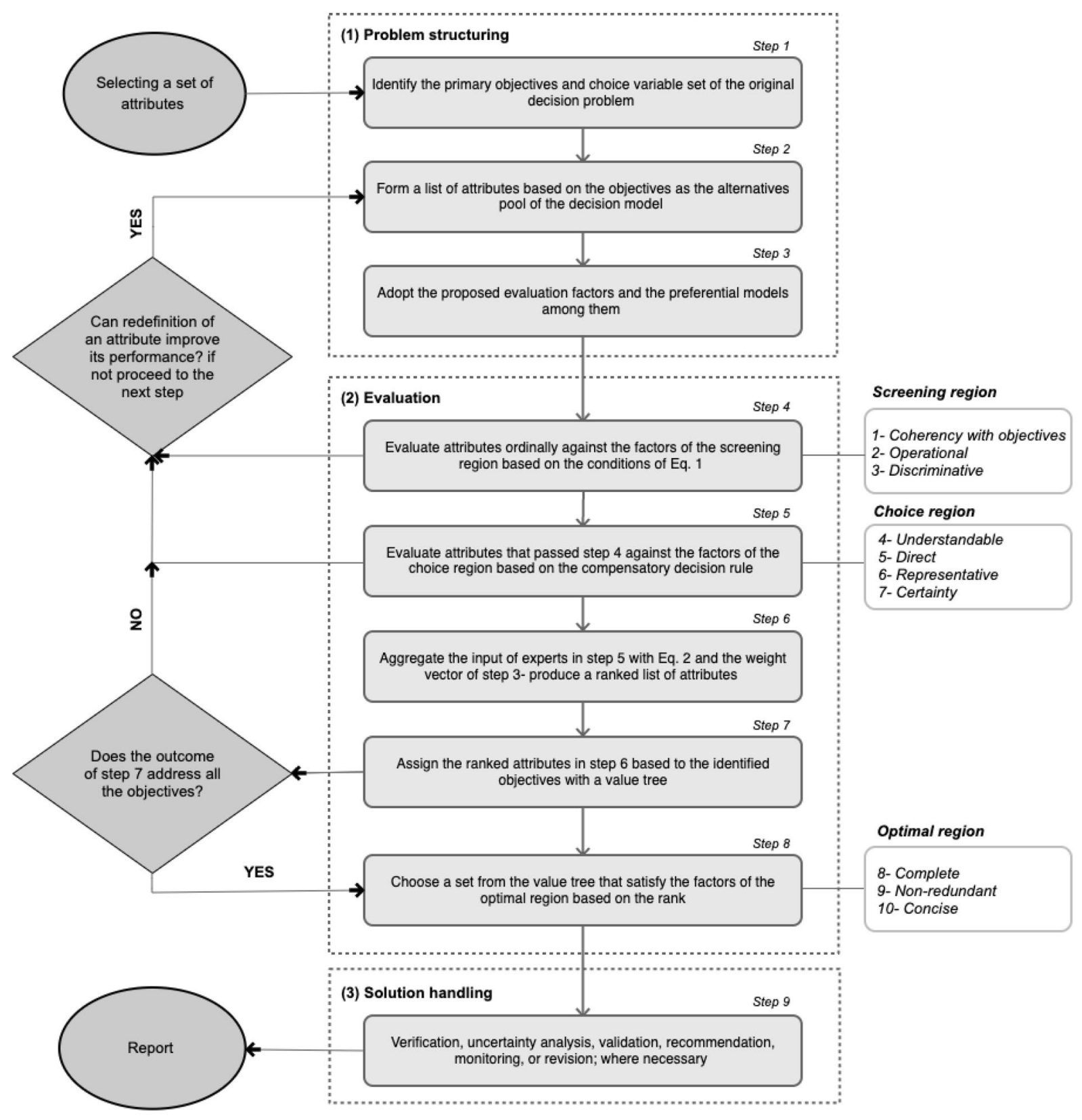

Fig. 2 The consecutive algorithm of the framework for the selection process of an attribute set

\subsection{Methods of implementation}

For obtaining a degree of validation and investigating the performance of the framework, we conducted an experiment to test the implementation of the framework in the context of mid-term disaster recovery planning of the Tehran transportation network. We sought to select an attribute set for optimizing the performance of the network recovery process after a major earthquake. In doing so, we collected data from literature of DRPTN and disaster recovery experts to obtain a list of candidate attributes as the input of the framework. A systematic literature review of 46 papers allowed us to extract 34 attributes from DRPTN publications. Additionally, we collected ten additional unique attributes from 23 decision-makers of crisis management organizations using a paper-administrated survey. Thereafter, we organized a workshop and followed the steps of the developed framework that is presented in Sect. 5.3. We acquired the input of a focus group that includes four senior members of a group of city planners and emergency managers who had previously developed the disaster recovery planning of transportation network. Before the evaluation session, we explained the structure and function of the framework and discussed the problem by presenting a brief disaster scenario as well 
as detailed descriptions and definitions of the evaluation factors. For the sake of consistency with a real-life instance of the DRPTN, we accepted the previously defined objectives for the same problem that the focus group had formulated. The objectives were maximizing accessibility and mobility as the properties of the network, and maximizing recovery effectivity and recovery efficiency as the properties of the recovery process.

At first, DMs evaluated the alternatives based on the three non-compensatory evaluation factors of the screening region and assigned a binary value of 1 or 0 . Following the noncompensatory decision rule shown in Eq. (1), alternatives were screened and transmitted to the choice region. In the next step, DMs used a direct rating on a local scale of 0 to 10. The group was also free to redefine the attributes that have not satisfied the evaluation factors of the screening region. DMs deliberated on the score of each attribute and communicated it verbally once a consensus was reached. This process varied for different attributes. Sometimes disagreements required more extended discussion to be resolved, particularly in the presence of an opposite voice, and in other cases, the value assignment process was relatively fast. In the screening region, three attributes have been excluded using a majority vote where no consensus could be reached. We observed that conflicts mainly occurred in the screening and optimal region, while the evaluation process in the choice region encountered some relatively minor disagreements resulting in less controversial discussion. In both screening and choice regions, critical issues were resolved by allowing experts to redefine or improve attributes that failed to meet non-compensatory evaluation factors. As subject-matter experts, participants had prior experience analyzing possible attributes for disaster recovery planning of transportation network and emergency network planning. Once the scores had been documented, we used the weight vector presented in Sect. 5.2 and Eq. (2) to aggregate DMs inputs and solve a utility choice problem that resulted in a ranked list of attributes. Consequently, we used a conceptual value tree of objectives to assist DMs in assigning each ranked attribute to the representative objectives. In the last step, DMs selected a set among ranked attributes which satisfied the optimal region's three factors and constituted the recommended set. The evaluation session took 3:07 min, while the total time of the subject-relevant discussion was 2:42 min.

Finally, to analyze the performance of the framework and the resulting attributes of the case study, we began by investigating the typology of the selected attributes according to Keeney's recommendations (Keeney 1992). Keeney characterized attributes as three different types: Natural, Proxy, and Constructed. Natural attributes directly measure the degree to which an objective is met and can be counted or physically measured. Proxy attributes share features of natural attributes but are less informative and do not directly indicate the achievement of an objective. Constructed attributes are developed when there are no natural attributes for the objective of the concern. The certainty and accuracy of these attributes might be less than Natural attributes with respect to measuring the objective, but their presence is essential in the absence of natural attributes (Keeney 2007). Secondly, we determined the source of inclusion of attributes in different stages of the evaluation process and in the ranked list of attributes to understand how the population of the attributes in each stage is distributed. Thirdly, we compared the resulting attributes of the framework to the list of working attributes previously selected by the participating experts for the same planning in the case area. Lastly, we obtained the focus group's feedback to two questions: (1) as users, to what degree are you satisfied with the application of the framework, and (2) to what degree do you agree with the improved quality of the framework's outcome compared to the previously selected attributes. We used an anonymously printed-format survey based on a 5-point Likert scale (Joshi et al. 2015) two days after the workshop. Additionally, we performed an unstructured group discussion with openended questions that lasted approximately $30 \mathrm{~min}$ immediately after the workshop, allowing DMs to openly communicate the experience of using the framework.

\section{Result and synthase}

\subsection{Performance of the framework in the implementation process}

We followed the steps of the framework and applied it to the Tehran DRPTN problem. Having 57 candidate attributes as the input of the framework, the screening region filtered $42 \%$ of alternatives that failed to meet at least one of the non-compensatory evaluation factors. Therefore, the compensatory evaluation in the choice region began with 33 attributes that formed $58 \%$ of the initial alternative pool. Table 3 highlights the number of alternatives in each stage of the evaluation process.

The outcome of the choice region yielded a ranked list of attributes that was preliminary to organizing a generic value tree based on the primary objectives. In the optimal region, the distribution of eight first ranked attributes to the objectives was required the way that all objectives receive at least one representative attribute. Similarly, DMs assigned the first 11 attributes to the value tree to provide each objective with no less than two attributes. To be able to provide three available choices for all four objectives, assigning 16 first ranked attributes was required. That supports the transmission of 16 attributes to the optimal region (approx. 26\% of the alternative 
pool). Table 4 shows the first 16 attributes assign to the four objectives until each objective receives at least three attributes.

Based on the arrangement of the rank attributes on the value tree, the DMs selected six attributes as the recommended set of decision attributes for the DRPTN problem. The set contains the first five ranked attributes as (1) access level to Service Providing (SP) nodes; (2) product of link travel delay and traffic flow; (3) travel time improvement per recovery duration; (4) travel time improvement per resources, and (5) centrality measures plus Link capacity that is ranked as the eighth attribute. The recommended set covers the main concerns of the decision problem based on the primary objectives and is supposed to be complete and non-redundant with an optimized size of the set. Table 5 provides a brief description of the selected attributes.

Table 6 demonstrates the properties of each selected attribute of the recommended set and their representing objectives. The calculated utility based on the compensatory factors as well as the rank of each attribute irrespectively indicates the score and ordinal importance of attributes. The selected set consists of four natural attributes, one constructed, and one proxy attribute. The range of the assigned utility of attributes was between 14.22 and 29.67 while the best utility could ideally be 30.3 , and 3.03 for the worst utility.

Table 3 Number and share of attributes in decision regions of the evaluation process

\begin{tabular}{llll}
\hline & Number & Share $(\%)$ & Examples \\
\hline Proceed into the screening region & 57 & 100 & Full list available at: https://doi.org/10.14279/depositonce-10019 \\
Filtered in the screening region & 24 & 42.1 & Lifeline interaction, traveler convince, link geometry, damage complexity \\
Proceed into the choice region & 33 & 58 & Depot and need points, traffic redundancy, centrality measures, redundancy \\
Proceed into the optimal region & 16 & 26 & Link topology, capacity, social vulnerability* link delay, recovery efficiency \\
\hline
\end{tabular}

Table 4 The generic distribution of the first 16 attributes to the respective primary objectives

\begin{tabular}{|c|c|c|c|c|c|}
\hline Objective & Rank 1 & Rank 2 & Ranke 3 & Rank 4 & Ranke 5 \\
\hline $\begin{array}{l}\text { Maximize recovery } \\
\text { effectivity }\end{array}$ & $\begin{array}{l}\text { Travel delay of link * link } \\
\text { flow }\end{array}$ & $\begin{array}{l}\text { Impact on Total Network } \\
\text { Travel Time }\end{array}$ & $\begin{array}{l}\text { Social vulnerability* link } \\
\text { flow }\end{array}$ & $\begin{array}{l}\text { Social vulner- } \\
\text { ability* } \\
\text { zone travel } \\
\text { demand }\end{array}$ & \\
\hline $\begin{array}{l}\text { Maximize recovery } \\
\text { efficiency }\end{array}$ & $\begin{array}{l}\text { Travel time improvement } \\
\text { per resources }\end{array}$ & $\begin{array}{l}\text { Travel time improve- } \\
\text { ment/recovery duration }\end{array}$ & Recovery efficiency & & \\
\hline Maximize accessibility & $\begin{array}{l}\text { Access level to the ser- } \\
\text { vice providing nodes }\end{array}$ & Centrality measures & $\begin{array}{l}\text { East-west and north- } \\
\text { south connectivity }\end{array}$ & $\begin{array}{l}\text { Connectivity } \\
\text { to other traf- } \\
\text { fic zones }\end{array}$ & Network topology \\
\hline Maximize mobility & Link capacity & $\begin{array}{l}\text { Annual average weekly } \\
\text { traffic }\end{array}$ & $\begin{array}{l}\text { Annual average daily } \\
\text { traffic }\end{array}$ & Traffic density & \\
\hline
\end{tabular}

Table 5 A brief description of attributes of the selected set

\begin{tabular}{|c|c|}
\hline Selected attributes & Brief description \\
\hline Access to service providing nodes & $\begin{array}{l}\text { The capability of links in providing access to the location of critical facilities and service } \\
\text { providing nodes on the network }\end{array}$ \\
\hline Link capacity & The ability of each link to carry the traffic as a measure of mobility performance of a link \\
\hline Travel time improvement (TTI) per resources & $\begin{array}{l}\text { The amount of machinery or monetary resources that have to be assigned to achieve a certain } \\
\text { improvement in travel time on the network }\end{array}$ \\
\hline Travel time improvement per recovery duration & The amount of required unit of time to achieve a defined travel time improvement in the network \\
\hline Travel delay $*$ link flow & $\begin{array}{l}\text { The travel delay time that closure of a link imposes to a specific } O-D \text { trip combined to the } \\
\text { amount of traffic volume that the link sustains }\end{array}$ \\
\hline Centrality measure & Topological importance of a link in a network graph regardless of the traffic flow \\
\hline
\end{tabular}


Table 6 Rank, calculated utility, representing objectives, and type of attributes of the selected set

\begin{tabular}{lllllll}
\hline Attribute & Access level to SP nodes & $\begin{array}{l}\text { Travel delay of } \\
\text { link * link flow }\end{array}$ & TTI/resources & TTI/recovery duration & Link centrality index & Link capacity \\
\hline Rank & $(1)$ & $(2)$ & $(3)$ & $(4)$ & $(5)$ & $(8)$ \\
Utility & 29.675 & 29.375 & 28.912 & 28.448 & 27.942 & 25.878 \\
Type & Natural & Constructed & Natural & Natural & Proxy & Natural \\
Objective & Accessibility & Effectivity & Efficiency & Efficiency & Accessibility & Mobility \\
\hline
\end{tabular}

\subsection{Synthesis of the framework implementation and feedback of participating DMs}

Table 7 shows that the literature of DRPTN contributes to $59.64 \%$ of the initial alternative pool while the survey with experts formed $17.54 \%$ of attributes. Additionally, 13 attributes $(22.8 \%)$ were added to the alternative pool during the evaluation process as by-products of the framework. Similar to the initial population of the alternative pool, in the first 10 and 20 ranked attributes, literature-based attributes have the largest share. In the selected set, half of the attributes belong to the literature review's output, while the rest were introduced during the workshop. Results show that while collected attributes from 23 disaster managers DMs occupy $22.8 \%$ of the population of the initial alternative pool, they contribute the least in all ranked attribute classes and have no representative within the selected set.

Table 8 shows the retrospective attributes which had been selected by participating DMs, for the same problem and the same geographical context as a set of DRPTN working attributes. Model-driven attributes refer to the attributes selected by DMs following the proposed framework of the current paper. Two sets share two identical attributes based on equal serving objectives. The size of the model-driven attribute set is six members and the working attribute set contains nine attributes.

With respect to the users of the framework, the results of the survey communicate a "moderately to strongly satisfactory" application of the framework while the majority of DMs were "strongly agree" with the quality of the framework's outcome as the selected attribute set of the DRPTN problem. Table 9 shows the response of the participants to the question addressing to what degree users were satisfied with the application of the framework and Table 10 is the response to the question that to what degree do they agree with the improved quality of the framework's outcome compared to the previously selected attributes.

During the open discussion after the workshop, DMs confirmed that it was not foreseen for them to select an attribute set that significantly differed from the one they had previously selected. All participants agreed that disciplined and structured evaluating of candidate attributes could lead them to revisit the current working set of attributes. Two DMs were not completely satisfied with the evaluation process in the choice region due to the number of alternatives. One DM expressed that the evaluation process in the choice region was not as easy as it was for the screening region with non-compensatory decision rules. Another DM took a similar stance and suggested a mechanism to reduce the size of the alternative set in the choice region, while two other participants found the evaluation process of the framework relatively easy to use. Finally, DMs responded positively to whether the resulting attribute set fairly reflects a complete range of their interests and values concerning the objectives of the planning.

\section{Discussion}

Based on the characteristics of the framework and analysis of its outcome, the following argument discusses the reasons why we believe the application of the framework was successful. First, since the screening region allows for pre-evaluation, the framework is inclusive and open to alternatives suggested by diverse sources such as experts' opinions and literature. The framework also accepts the redefined attributes during the evaluation process which not only increases the likelihood of reaching a complete set of attributes, but also provides a basis for brainstorming, critical thinking, and creative input into the model. Harnessing the benefit of integration of compensatory and non-compensatory techniques, alternatives are evaluated in a thorough yet manageable manner. Therefore, although the modeled process is flexible in accepting alternatives as inputs, it is rigorous in evaluating them since only $26 \%$ of attributes from the alternative pool proceeded into the optimal region and above $42 \%$ of attributes were filtered in the screening region. Additionally, $100 \%$ of alternatives were evaluated at least once, while at least two stages of evaluation took place for $52 \%$ of alternatives, and $26 \%$ of alternatives have been assessed three times. Filtering $42 \%$ of attributes in the screening region could suggest a rigorous screening process due to the number of attributes in the alternative pool. Pre-evaluation or size of the alternative pool could impact this process, while the trade-off 
Table 7 Distribution of attributes based on their source in the initial pool, first 5,10 , and 20 ranked attributes

\begin{tabular}{|c|c|c|c|c|c|c|c|c|c|c|c|c|}
\hline \multirow[b]{2}{*}{ Redefined } & \multicolumn{2}{|c|}{ Selected set } & \multicolumn{2}{|c|}{$\begin{array}{l}\text { The first } \\
5 \text { ranked } \\
\text { attributes }\end{array}$} & \multicolumn{2}{|c|}{$\begin{array}{l}\text { The first } \\
10 \text { ranked } \\
\text { attributes }\end{array}$} & \multicolumn{2}{|c|}{$\begin{array}{l}\text { The first } \\
20 \text { ranked } \\
\text { attributes }\end{array}$} & \multicolumn{2}{|c|}{$\begin{array}{l}33 \text { attributes } \\
\text { of the choice } \\
\text { region }\end{array}$} & \multicolumn{2}{|c|}{$\begin{array}{l}\text { The initial } \\
\text { alternative } \\
\text { pool }\end{array}$} \\
\hline & 3 & $50 \%$ & 3 & $60 \%$ & 3 & $30 \%$ & 6 & $30 \%$ & 10 & $30.3 \%$ & 13 & $22.8 \%$ \\
\hline Experts Survey & 0 & $0 \%$ & 0 & $0 \%$ & 3 & $30 \%$ & 4 & $20 \%$ & 7 & $21.2 \%$ & 10 & $17.54 \%$ \\
\hline Literature & 3 & $50 \%$ & 2 & $40 \%$ & 4 & $40 \%$ & 10 & $50 \%$ & 16 & $48.5 \%$ & 34 & $59.64 \%$ \\
\hline
\end{tabular}

Table 8 An overview of the selected attributes by the framework and previously selected attributes by the DMs in an unaided process

\begin{tabular}{|c|c|c|c|c|c|}
\hline \multirow[t]{2}{*}{ Attribute sets } & \multicolumn{4}{|l|}{ Objectives } & \multirow[t]{2}{*}{$\overline{\text { Set size }}$} \\
\hline & Accessibility & Effectivity & Efficiency & Mobility & \\
\hline Model-driven Attribute & $\begin{array}{l}\text { Access level to SP nodes, } \\
\text { Link centrality index }\end{array}$ & $\begin{array}{l}\text { Travel delay of link * link } \\
\text { flow }\end{array}$ & $\begin{array}{l}\text { TTI/resources, TTI/recov- } \\
\text { ery duration }\end{array}$ & Link capacity & 6 \\
\hline Working attributes & $\begin{array}{l}\text { Access level to critical } \\
\text { nodes, access to main } \\
\text { highways, west-east: } \\
\text { north-south connectivity }\end{array}$ & $\begin{array}{l}\text { Proximity population, Peak } \\
\text { hour traffic flow }\end{array}$ & $\begin{array}{l}\text { Traffic flow improvement/ } \\
\text { resource, Recovery } \\
\text { duration }\end{array}$ & Link capacity, Density & 9 \\
\hline
\end{tabular}

Table 9 Agreement degree to the quality of the selected

\begin{tabular}{llllll}
\hline Strongly agree & $\begin{array}{l}\text { Mod- } \\
\text { erately } \\
\text { agree }\end{array}$ & Neutral & $\begin{array}{l}\text { Moderately } \\
\text { disagree }\end{array}$ & $\begin{array}{l}\text { Strongly } \\
\text { disagree }\end{array}$ \\
\hline DM1 & $\times$ & & & \\
DM2 & $\times$ & & & \\
DM3 & $\times$ & $\times$ & & \\
DM4 & & & & \\
\hline
\end{tabular}

Table 10 Satisfaction degree for using the framework set

\begin{tabular}{lllll}
\hline & $\begin{array}{l}\text { Strongly } \\
\text { satisfied }\end{array}$ & $\begin{array}{l}\text { Moderately Neutral } \\
\text { satisfied }\end{array}$ & $\begin{array}{l}\text { Moderately } \\
\text { dissatisfied }\end{array}$ & $\begin{array}{l}\text { Strongly } \\
\text { dissatis- } \\
\text { fied }\end{array}$ \\
\hline DM1 & $\times$ & & & \\
DM2 & & $\times$ & & \\
DM3 & & $\times$ & & \\
DM4 & $\times$ & & & \\
\hline
\end{tabular}

between the completeness of the input attribute list and the rigor of the process should be taken into account.

Secondly, the framework remains contextual and problem-dependent because the evaluation process relies on the primary objectives of the original problem as the benchmark for the selection of candidate attributes (steps 1 and 2), evaluation (steps 4 and 5), and identifying the generic class of attributes for the final selection (steps 7 and 8). Furthermore, the dependency of the framework on the decision context resulted in the presence of four natural attributes in the selected set, which suggests the directness of the attribute set and context-centric performance of the framework. Moreover, the model not only evaluates individual attributes but also appraises the properties of desirable sets of attributes of the targeted problem, ensuring the non-redundancy and completeness of the set based on the primary objectives.

Thirdly, the framework does not impose a significant cognitive burden because the evaluation factors are divided into three independent regions with a maximum size of four factors in a flat hierarchy format. It allows that individual judgments, in both articulating preferences among four compensatory evaluation factors and value assessments, remain in a relatively reasonable state (Bond et al. 2008; Marttunen et al. 2017; Cowan 2010). Furthermore, it was evident from the implementation process and participants' feedback that the structured framework promotes an amount of supervision over the inevitable subjectivity associated with the attribute selection by allowing to track and locate where subjectivity might influence the evaluation process. Hence, the selected attributes are less likely to be prone to bias and error than attributes selected without a systematic, tractable, and transparent procedure. Based on the post-workshop survey, the model-driven attributes meaningfully integrated the concerns, values, and interests of the DMs into the decision analysis with a reduced size of the set compared to the previously selected attributes. However, we cannot dismiss the possibility that the positive feedback of the DMs could have originated from availability heuristic, courtesy, etc., and future research must re-implement this methodology in different settings.

Finally, the share of the redefined attributes during the workshop in the selected set, first 10, and 20 list of attributes suggests that the framework is likely to promote creative and critical thinking. Additionally, we observed that 
the evaluation factors and the evaluation process framed the discussion and provided a ground for brainstorming and collaborative decision-making. Moreover, according to Table 7, while the academic literature provided $50 \%$ of attributes of the selected set, DMs' local knowledge contributes to the other half of the attribute set which indicates the performance of the framework with regard to balance incorporation of available knowledge sources.

Different preference elicitation techniques deliver different weights and the same holds for different experts. While weighting vectors mainly depend on the method and experts that generate them, uncertainty regarding the used preference elicitation method in this study still stands. Using any preference elicitation method due to the absence of a known solution or "true weight" cannot claim superiority. More evidence from the application of the employed method is needed to provide a level of confidence in the trustworthiness of the generated weights. The preference elicitation process could be subjected to re-implementation, uncertainty analysis, or a wider domain of analysis to increase confidence in the robustness of weights. There are two types of uncertainty involved within the process of the framework. First is the uncertainty related to the application of the attributes in terms of measuring DRPTN objectives, and second is the uncertainty of the selection process. Uncertainty within the selection process can be related to the individual subjective value assignment, group dynamics, and preference determination. Uncertainty of attributes application is due to the lack of experimental investigation on the quality of attributes. Further evidence is required from (1) the application of this framework in different settings and (2) the application of the produced attributes in real-life problems or modeled disaster scenarios. For the former, we invite studies to employ the proposed framework, while the latter, we aim to address it in future research.

The developed framework can offer a practical application in the disaster resilient infrastructure context as it can support the problem structuring of these problems by facilitating the identification of problem-relevant decision attributes. The same process can (supposedly) be applied to other similar contexts, since selecting decision attributes is the primary and critical step of decision analysis and modeling in general, particularly when the popularity of MCDA in environmental, engineering, and management studies is growing (Keisler and Linkov 2014; Bruen 2021). Employing a systematically selected set of attributes for decision models could reduce the uncertainty related to decision factors in multi-objective or multi-criteria decision-making models. This study suggests that in the problem-structuring phase of decision modeling, analysts employ the suggested framework or any other systematic attribute selection process to increase the likelihood of achieving a viable attribute set.

\section{Conclusion}

While social and infrastructure systems encounter an unprecedented risk of climate change and natural hazards, it is of paramount significance to develop DSSs that pave the way for informed collaborative decision-making. Doing so, modelers should feed the decision models with equitable and plausible attributes that are the result of a tenable systematic selection framework. This study sought to bridge the identified knowledge gap in the problem structuring of multicriteria decision problems by proposing a choice-screening model to assist in the evaluation of decision attributes and prescribe a set. We illustrated the developed framework with a case study to select decision attributes of a disaster recovery planning problem. The innovative integration of compensatory and non-compensatory aggregation methods within a newly designed sequential, 3-stage evaluation process constituted the developed framework. The formalized attribute selection process facilitated harnessing DMs' knowledge and consequently led to a set of attributes of the case problem. DMs were able to systematically evaluate attributes and collaboratively produce a ranked list of attributes as well as the final selected set. We investigated the performance of the framework based on the typology of the produced results, the discussed characteristics of the framework, and the feedback from users. Observing the development of the discussion in the workshop and position of the redefined attributes in the final rank, it is not implausible to conclude that the evaluation mechanism within the framework facilitates critical and creative brainstorming, thus fostering the incorporation of the available knowledge sources. Therefore, the preliminary investigations suggest the successful application of the framework in evaluating and selecting an equitable and tenable set of attributes. However, further evidence from field experiments or simulated implementation is required to support the quality of the selected set.

This question of the extent to which decision aid interventions are successful in controlling the subjectivity and guiding the intuitive feelings to rational judgments has been discussed widely in other disciplines. However, data-driven, systematic, or evidence-based approaches do not always make a decision-making process immune to epistemological errors (Power et al. 2019). Therefore, we cannot rule out a possible implication of common cognitive biases prevalent in many decision processes. Nevertheless, it is reasonable to assume that the systematic attribute selection process could allow analysts to track and locate where subjectivity might influence the evaluation process. For further use of this framework, we suggest that a moderator oversees the evaluation session and acts as an opposite voice, if necessary, to facilitate the 
extraction and formalization of DMs' knowledge. Using the proposed framework, one must take into account the size and completeness of the alternative set. A so-called diverse complete set of alternatives is required since the result will be as complete as the alternative pool. Nevertheless, analysts and further users of the framework must establish a balance between the desired completeness and the complexity of the model. One should also note that the effectiveness of the selected set remains dependent on the recognition of the right problem and consequently defining the right objectives, since the framework remains true to the defined primary objectives of the decision problem. Research and practice can both use the proposed framework for establishing an equitable set of attributes of decision problems, and even one who is not necessarily an expert in decision analysis. While dealing with any decision context involving multiple criteria, a systematic approach towards the identification and selection of decision attributes need to be employed. More time and effort must be dedicated to a formal problem-structuring phase before formulating a decision problem, specifically with regard to complex and critical problems, such as those which address environmental challenges, risk assessment, and disaster resilience planning.

Acknowledgements We would like to acknowledge the contribution of three anonymous reviewers (especially "reviewer 2") for their valuable insights and comments towards improving this paper.

Funding Open Access funding enabled and organized by Projekt DEAL.

\section{Declarations}

Conflict of interest The authors have no conflict of interest with regard to the content of this manuscript.

Open Access This article is licensed under a Creative Commons Attribution 4.0 International License, which permits use, sharing, adaptation, distribution and reproduction in any medium or format, as long as you give appropriate credit to the original author(s) and the source, provide a link to the Creative Commons licence, and indicate if changes were made. The images or other third party material in this article are included in the article's Creative Commons licence, unless indicated otherwise in a credit line to the material. If material is not included in the article's Creative Commons licence and your intended use is not permitted by statutory regulation or exceeds the permitted use, you will need to obtain permission directly from the copyright holder. To view a copy of this licence, visit http://creativecommons.org/licenses/by/4.0/.

\section{References}

Alexander DE (2013) Resilience and disaster risk reduction: an etymological journey. Nat Hazards Earth Syst Sci 13:2707-2716. https://doi.org/10.5194/nhess-13-2707-2013
Alfares HK, Duffuaa SO (2008) Assigning cardinal weights in multicriteria decision making based on ordinal ranking. J Multi-Crit Decis Anal 15:125-133. https://doi.org/10.1002/mcda.420

Aydin NY, Duzgun H, Heinimann H, Wenzel F, Gnyawali KR (2018) Framework for improving the resilience and recovery of transportation networks under geohazard risks. Int J Disaster Risk Reduct 31:832-843

Baker D, Bridges D, Hunter R et al (2001) Guidebook to decisionmaking methods. US Department of Energy Washington, DC, WSRC-IM-2002-00002

Barfod MB, Leleur S (eds) (2014) Multi-criteria decision analysis for use in transport decision making. 2 edn, DTU Transport, DTU Lyngby

Barron FH, Barrett BE (1996) Decision quality using ranked attribute weights. Manag Sci 42:1515-1523

Beling PA (2013) Multi-scale decision making: challenges in engineering and environmental systems. Environ Syst Decis 33:323325. https://doi.org/10.1007/s10669-013-9469-y

Belton V (1999) Multi-criteria problem structuring and analysis in a value theory framework. In: Gal T, Stewart T, Hanne T (eds) Multicriteria decision making, advances in MCDM-models, algorithms, theory, and applications. Kluwer Academic Publishers, Dordrecht, pp 12-132

Belton V, Stewart T (2012) Multiple criteria decision analysis: an integrated approach. Springer, New York

Bond SD, Carlson KA, Keeney RL (2008) Generating objectives: can decision makers articulate what they want? Manag Sci 54(1):56-70. https://doi.org/10.1287/mnsc.1070.0754

Bruen M (2021) Uptake and dissemination of multi-criteria decision support methods in civil engineering-lessons from the literature. Appl Sci 11:2940. https://doi.org/10.3390/app11072940

Bruneau M, Chang SE, Eguchi RT et al (2003) A Framework to quantitatively assess and enhance the seismic resilience of communities. Earthq Spectra 19(4):733-752. https://doi.org/ 10.1193/1.1623497

Caruzzo A, Blanco CMR, Joe P (2020) Developing a multiattribute decision aid model for selection of a weather radar supplier. Environ Syst Decis. https://doi.org/10.1007/ s10669-020-09770-3

Cegan JC, Filion AM, Keisler JM et al (2017) Trends and applications of multi-criteria decision analysis in environmental sciences: literature review. Environ Syst Decis 37:123-133. https://doi.org/ 10.1007/s10669-017-9642-9

Cinelli M, Spada M, Kim W et al (2020) MCDA Index Tool: an interactive software to develop indices and rankings. Environ Syst Decis. https://doi.org/10.1007/s10669-020-09784-x

Clemen RT (1996) Making hard decisions: an introduction to decision analysis, 2nd edn. Duxbury Press, Pacific Grove

Convertino M, Baker KM, Vogel JT et al (2013) Multi-criteria decision analysis to select metrics for design and monitoring of sustainable ecosystem restorations. Ecol Ind 26:76-86

Corner J, Buchanan J, Henig M (2001) Dynamic decision problem structuring. J Multi-Crit Decis Anal 10:129-141. https://doi.org/ $10.1002 /$ mcda. 295

Cowan N (2010) The magical mystery four: how is working memory capacity limited, and why? Curr Dir Psychol Sci 19(1):51-57. https://doi.org/10.1177/0963721409359277

Dale VH, Efroymson RA, Kline KL, Davitt MS (2015) A framework for selecting indicators of bioenergy sustainability. Biofuels Bioprod Biorefin 9(4):435-446. https://doi.org/10.1002/bbb.1562

Danielson M, Ekenberg L (2016) The CAR method for using preference strength in multi-criteria decision making. Group Decis Negot 25:775-797. https://doi.org/10.1007/s10726-015-9460-8

Desmond M (2007) Decision criteria for the identification of alternatives in strategic environmental assessment. Impact Assess 
Project Apprais 25(4):259-269. https://doi.org/10.3152/14615 5107X269067

Dodgson J, Spackman M, Pearman AD, Phillips LD (2009) Multicriteria analysis: a manual. Department of the Environment, London: Department of the Environment, Transport and the Regions

Elboshy B, Kanae S, Gamaleldin M et al (2019) A framework for pluvial flood risk assessment in Alexandria considering the coping capacity. Environ Syst Decis 39:77-94. https://doi.org/10.1007/ s10669-018-9684-7

Fekete A (2019) Social vulnerability (Re-)assessment in context to natural hazards: review of the usefulness of the spatial indicator approach and investigations of validation demands. Int J Disaster Risk Sci 10:220. https://doi.org/10.1007/s13753-019-0213-1

Fox-Lent C, Bates ME, Linkov I (2015) A matrix approach to community resilience assessment: an illustrative case at Rockaway Peninsula. Environ Syst Decis 35:209-218

Franco AL, Montibeller G (2010) Problem structuring for multi-criteria decision analysis interventions. Working Paper 09(115), pp 1-25

Gigerenzer G, Gaissmaier W (2011) Heuristic decision making. Annu Rev Psychol 62(1):451-482. https://doi.org/10.1146/annur ev-psych-120709-145346

Gigerenzer G, Goldstein DG (1996) Reasoning the fast and frugal way: models of bounded rationality. Psychol Rev 103:650-669

Girod M et al (2003) Decision making in conceptual engineering design: an empirical investigation. Proc Inst Mech Eng Part B 217(9):1215-1228

Goujon B, Labreuche C (2015) Use of a multi-criteria decision support tool to prioritize reconstruction projects in a post-disaster phase. In: ICTDM 2015, Rennes

Gregory R, Failing L (2002) Using decision analysis to encourage sound deliberation: water use planning in British Columbia, Canada. J Pol Anal Manag 21:492-499. https://doi.org/10.1002/ pam.10059

Ha MH, Yang Z (2018) Modelling interdependency among attributes in MCDM: its application in port performance measurement. In Lee PT-W, Yang Z (eds), Multi-criteria decision making in maritime studies and logistics, International Series in Operations Research \& Management Science 260

Hämäläinen R, Alaja S (2008) The threat of weighting biases in environmental decision analysis. Ecol Econ 68:556-569

Herrera H, Kopainsky B (2020) Using system dynamics to support a participatory assessment of resilience. Environ Syst Decis. https:// doi.org/10.1007/s10669-020-09760-5

Höfer S, Ziemba A, El Serafy GA (2020) Bayesian approach to ecosystem service trade-off analysis utilizing expert knowledge. Environ Syst Decis 40:67-83. https://doi.org/10.1007/s10669-019-09742-2

Huang IB, Keisler J, Linkov I (2011) Multi-criteria decision analysis in environmental sciences: ten years of applications and trends Science of the Total Environment. Sci Total Environ 409:3578-3594

Jacobi SK, Hobbs B (2007) Quantifying and mitigating the splitting bias and other value tree-induced weighting biases. Decis Anal 4:194-210

Joshi A, Saket K, Satish K et al (2015) Likert scale: explored and explained. Br J Appl Sci Technol 7:396-403

Kahneman D, Slovic P, Tversky A (1982) Judgment under uncertainty: heuristics and biases. Cambridge University Press, New York

Kárný M (2013) Automated preference elicitation for decision making. In: Guy T, Karny M, Wolpert D (eds) Decision making and imperfection studies in computational intelligence, vol 474. Springer, Berlin

Kassem A, Al-Haddad K, Komljenovic D, Schiffauerova A (2016) A value tree for identification of evaluation criteria for solar thermal power technologies in developing countries. Sustain Energy Technol Assess 16:18-32

Keeney R (1982) Decision analysis: an overview. Oper Res 30(5):803-838
Keeney R (1992) Value focused thinking: a path to creative decision making. Harvard University Press, Cambridge

Keeney R (2007) Developing objectives and attributes. In: Edwards W, Miles RF, von Winterfeldt D (eds) Advances in decision analysis. Cambridge University Press, New York

Keeney R, Gregory R (2005) Selecting attributes to measure the achievement of objectives. Oper Res 53:1-11

Keeney R, Raiffa H (1993) Decisions with multiple objectives: preferences and value trade-offs, 2nd edn. Cambridge University Press, Cambridge

Keeney RL, McDaniels TL (1992) Value-focused thinking about strategic decisions at BC hydro. INFORMS J Appl Anal 22(6):94-109

Keisler J, Linkov I (2014) Models, decisions and environment. Environ Syst Decis 34:369-372

Koks E, Rozenberg J, Zorn C et al (2019) A global multi-hazard risk analysis of road and railway infrastructure assets. Nat Sustain 10:1-11

Kunsch PL, Ishizaka A (2019) A note on using centroid weights in additive multi-criteria decision analysis. Eur J Oper Res 277(1):391-393

Kurth M, Kozlowski W, Ganin A, Mersky AC, Leung B, Dykes J, Kitsak M, Linkov I (2020) Lack of resilience in transportation networks: economic implications. Transp Res Part D 86:102419

Lin T, Lin JY, Cui SH, Cameron S (2009) Using a network framework to quantitatively select ecological indicators. Ecol Indic 9:1114-1120

Linkov I, Eisenberg DA, Bates ME, Chang D, Convertino M, Allen JH, Seager TP (2013) Measurable resilience for actionable policy. Environ Sci Technol 47(18):10108-10110

Linkov I, Fox-Lent C, Read L et al (2018) Tiered approach to resilience assessment. Risk Anal 38(9): 1772-1780

Liu Y, McNeil S, Hackl J, Adey B (2020) Prioritizing transportation network recovery using a resilience measure. Sustain Resilient Infrastruct. https://doi.org/10.1080/23789689.2019.1708180

Ma W, Luo X, Jiang Y (2017) Multicriteria decision making with cognitive limitations: a ds/ahp-based approach. Int J Intell Syst 32(7):686-721

Maier K, Stix V (2013) A semi-automated approach for structuring multi criteria decision problems. Eur J Oper Res 225(3):487-496

Majumder M (2015) Impact of urbanization on water shortage in face of climatic aberrations, pp 35-48. https://doi.org/10.1007/ 978-981-4560-73-3

Manyaga F, Nilufer N, Hajaoui Z (2020) A systematic literature review on multi-criteria decision making in disaster management. Int $\mathbf{J}$ Bus Ecosyst 2(2):1-7. https://doi.org/10.36096/ijbes.v2i2.197

Marttunen M, Belton V, Lienert J (2017) Are objectives hierarchy related biases observed in practice? A meta-analysis of environmental and energy applications of Multi-Criteria Decision Analysis. Eur J Oper Res

McDaniels TL, Chang SE, Hawkins D et al (2015) Towards disasterresilient cities: an approach for setting priorities in infrastructure mitigation efforts. Environ Syst Decis 35:252-263. https://doi.org/ 10.1007/s10669-015-9544-7

McIntosh RD, Becker A (2020) Applying MCDA to weight indicators of seaport vulnerability to climate and extreme weather impacts for US North Atlantic ports. Environ Syst Decis. https://doi.org/ 10.1007/s10669-020-09767-y

Merad M, Dechy N, Marcel F et al (2013) Multiple-criteria decisionaiding framework to analyze and assess the governance of sustainability. Environ Syst Decis 33:305-321. https://doi.org/10.1007/ s10669-013-9447-4

Mirzaee S, Fannon D, Ruth M (2019) A comparison of preference elicitation methods for multi-criteria design decisions about resilient and sustainable buildings. Environ Syst Decis 39:439-453. https:// doi.org/10.1007/s10669-019-09726-2 
Mitroff II, Featheringham TR (1974) On systemic problem solving and the error of the third kind. Behav Sci 19:383-393

Munda G (2005) Multi-criteria analysis. In: Proops J, Safonov P (eds) Modelling in ecological economics. Edward Elgar, NERA (National Economic Research Associates)

Niemeijer D, de Groot RS (2006) A conceptual framework for selecting environmental indicator sets. Ecol Indic 8:14-25

Otto SA, Kadin M, Casini M et al (2018) A quantitative framework for selecting and validating food web indicators. Ecol Indic 84:619631. https://doi.org/10.1016/j.ecolind.2017.05.045

Pearson J, Punzo G, Mayfield M et al (2018) Flood resilience: consolidating knowledge between and within critical infrastructure sectors. Environ Syst Decis 38:318-329. https://doi.org/10.1007/ s10669-018-9709-

Power DJ, Cyphert DR, Roth RM (2019) Analytics, bias, and evidence: the quest for rational decision making. J Decis Syst 28(2):120 137. https://doi.org/10.1080/12460125.2019.1623534

Quigley MC, Bennetts LG, Durance P et al (2019) The provision and utility of science and uncertainty to decision-makers: earth science case studies. Environ Syst Decis 39:307-348. https://doi.org/ 10.1007/s10669-019-09728-0

Rand K, Kurth M, Fleming CH, Linkov I (2020) A resilience matrix approach for measuring and mitigating disaster-induced population displacement. Int J Disaster Risk Reduct 42:e101310

Roberts R, Goodwin P (2002) Weight approximations in multi-attribute decision models. J Multi-Crit Decis Anal 11:291-303. https://doi. org $/ 10.1002 /$ mcda. 320

Rossberg AG, Uusitalo L, Berg T, Zaiko A, Chenuil A, Uyarra MC, Borja A, Lynam CP (2017) Quantitative criteria for choosing targets and indicators for sustainable use of ecosystems. Ecol Indic 72:215-224. https://doi.org/10.1016/j.ecolind.2016.08.005

Roszkowska E (2013) Rank ordering criteria weighting methodsa comparative overview. Optimum Studia Ekonomiczne 5(65): 14-33

Rothrock L, Yin J (2008) Integrating compensatory and noncompensatory decision-making strategies in dynamic task environments. In: Kugler T, Smith JC, Connolly T, Son YJ (eds) Decision modeling and behavior in complex and uncertain environments, vol 21. Springer, New York

Rouhanizadeh B, Kermanshachi S (2019) Investigating the relationships of socioeconomic factors delaying post-disaster reconstruction. Comput Civil Eng 33-40. https://doi.org/10.1061/ 9780784482445.005

Roy B (1996) Multicriteria methodology for decision aiding. Kluwer, Dordrecht

Salo AA, Hamalainen RP (2001) Preference ratio in multiattribute evaluation (PRIME)- elicitation and decision procedures under incomplete information. IEEE Trans Syst Man Cybern Part A 31(6):533-545

Sandri O, Hayes J, Holdsworth S (2020) Regulating urban development around major accident hazard pipelines: a systems comparison of governance frameworks in Australia and the UK. Environ Syst Decis. https://doi.org/10.1007/s10669-020-09785-w

Tiesmeier DK (2016) MCDM problem-structuring framework and a real estate decision support model. University of Manchester, Manchester

Tversky A (1972) Elimination by aspects: a theory of choice. Psychol Rev 79:77-94

Vaidya A, Mayer LA (2016) Criteria and indicators for a bioenergy production industry identified via stakeholder participation. Int $\mathrm{J}$ Sustain Dev World Ecol 23(6):526-540

Von Winterfeldt D, Fasolo B (2009) Structuring decision problems: a case study and reflections for practitioners. Eur J Oper Res 199(3):857-866

Walpole EH, Toman E, Stidham M et al (2020) The science and practice of ecological restoration: a mental models analysis of restoration practitioners. Environ Syst Decis. https://doi.org/10.1007/ s10669-020-09768-x

Yu H, Solvang WD (2017) A multi-objective location-allocation optimization for sustainable management of municipal solid waste. Environ Syst Decis 37:289-308. https://doi.org/10.1007/ s10669-017-9632-y

Zamanifar M, Hartmann T (2020) Optimization-based decision-making models for disaster recovery and reconstruction planning of transportation networks. Nat Hazards. https://doi.org/10.1007/ s11069-020-04192-5

Zamanifar M, Hartmann T (2021) Decision attributes for disaster recovery planning of transportation networks: a case study. Transp Res Part D 93:102771. https://doi.org/10.1016/j.trd.2021.102771

Zhang W, Wang N, Nicholson C (2017) Resilience-based post-disaster recovery strategies for road-bridge networks. Struct Infrastruct Eng. https://doi.org/10.1080/15732479.2016.1271813 